\section{Chondromyxoid Fibroma of the Finger}

So-Min Hwang, Ka-Hyung Cho, Hyung-Do Kim, Yong-Hui Jung, Hong-Il Kim

Aesthetic, Plastic and Reconstructive Surgery Center, Good Moonhwa Hospital, Busan, Korea

Correspondence: So-Min Hwang

Aesthetic, Plastic and Reconstructive Surgery Center, Good Moonhwa Hospital, 119 Beomil-ro, Dong-gu, Busan 601-803, Korea

Tel: +82-51-630-0199, Fax: +82-51-630-0145, E-mail: mdoc98@ hanmail.ne

No potential conflict of interest relevant to this article was reported.

Received: 24 Jul 2013 • Revised: 13 Aug 2013 • Accepted: 13 Aug 2013 pISSN: 2234-6163 • elSSN: 2234-6171

http://dx.doi.org/10.5999/aps.2014.41.3.302 • Arch Plast Surg 2014;41:302-304

Copyright (C) 2014 The Korean Society of Plastic and Reconstructive Surgeons

This is an Open Access article distributed under the terms of the Creative Commons

Attribution Non-Commercial License (http://creativecommons.org/licenses/by-nc/3.0/) which permits unrestricted non-commercial use, distribution, and reproduction in any medium, provided the original work is properly cited.

A 35-year-old man visited us with a chief complaint of painful swelling of the finger. A physical examination revealed a palpable mass, measuring approximately 2 $\mathrm{cm} \times 1 \mathrm{~cm}$, on the dorsoradial side of the base of the middle phalanx of the right index finger (Fig. 1A). Upon history taking, we found that the mass had formed 7 to 8 years before and had since grown slowly. The mass had a firm, hard, discrete, and immobile consistency. An X-ray revealed a translucent, osteolytic lesion at the base of the middle phalanx; this lesion was eccentrically located to the cortex (Fig. 1B). The lesion was a mass with an ovoid shape and was parallel to the long axis of the bone; it had a slightly marginal sclerotic border. Moreover, it exhibited expansile growth to the adjacent soft tissue on the dorsoradial side. On the basis of these findings, we made a $2-\mathrm{cm}$ straight, longitudinal incision on the radial side of the dorsum of the middle phalanx, thus confirming the presence of a bulging well-circumscribed cartilaginous-appearing mass (Fig. 2A). We performed an extensive, aggressive curettage of the lesion. The resulting bony defect was filled using iliac bone graft and screw fixation. In the resected specimen, there was a yellowish-white lobulated mass of $2 \mathrm{~cm} \times 1 \mathrm{~cm} \times 1 \mathrm{~cm}$ in size (Fig. 2B). On histopathological examination the mass mainly had a myxomatous appearance and was characterized by the lobular arrangement of stellate or spindle-shaped cells. The lobule was well circumscribed by fine fibrous septa and was composed of the central hypocellular area and the peripheral hypercellular area (Fig. 3). On the basis of these findings, we established a diagnosis of chondromyxoid fibroma (CMF). In the 15-month postoperative follow-up, the patient underwent an uneventful course without recurrent or metastatic episodes.

CMF was first described by Jaffe and Lichtenstein in 1948, and it is a rare, slowly growing benign bone tumor of cartilaginous origin. It accounts for less than $1 \%$ of all the primary bone tumors and less than $2 \%$ of benign bone tumors. Approximately $80 \%$ of the total cases occur in individuals aged 36 years or younger.
Fig. 1.

Preoperative findings. (A) Clinical photograph of the right index finger with a visible mass protruding from the dorsoradial side of the middle phalanx. (B) Preoperative anteroposterior $X$-ray film of the right index finger reveals

radiolucent tumor in the metaphyseal-diaphyseal area of the middle phalanx.
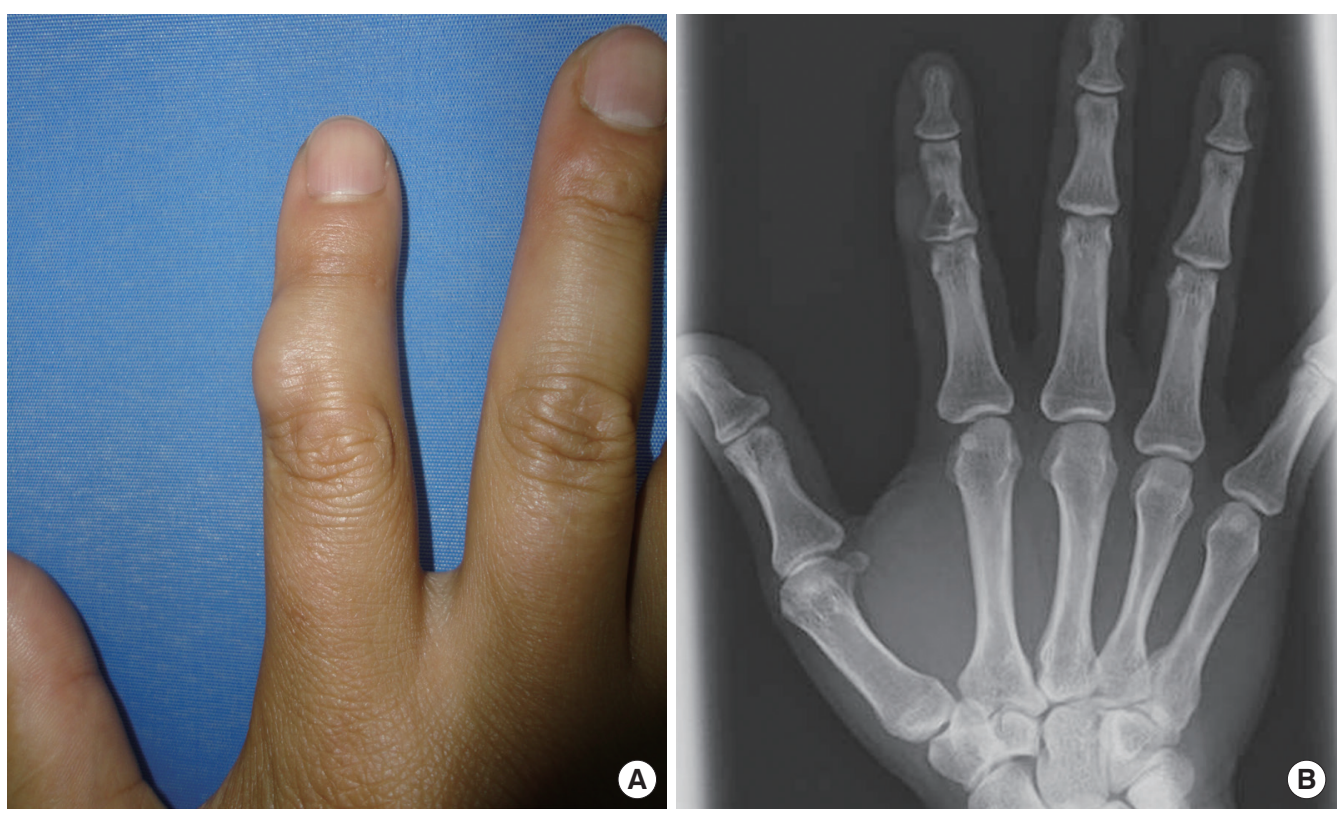

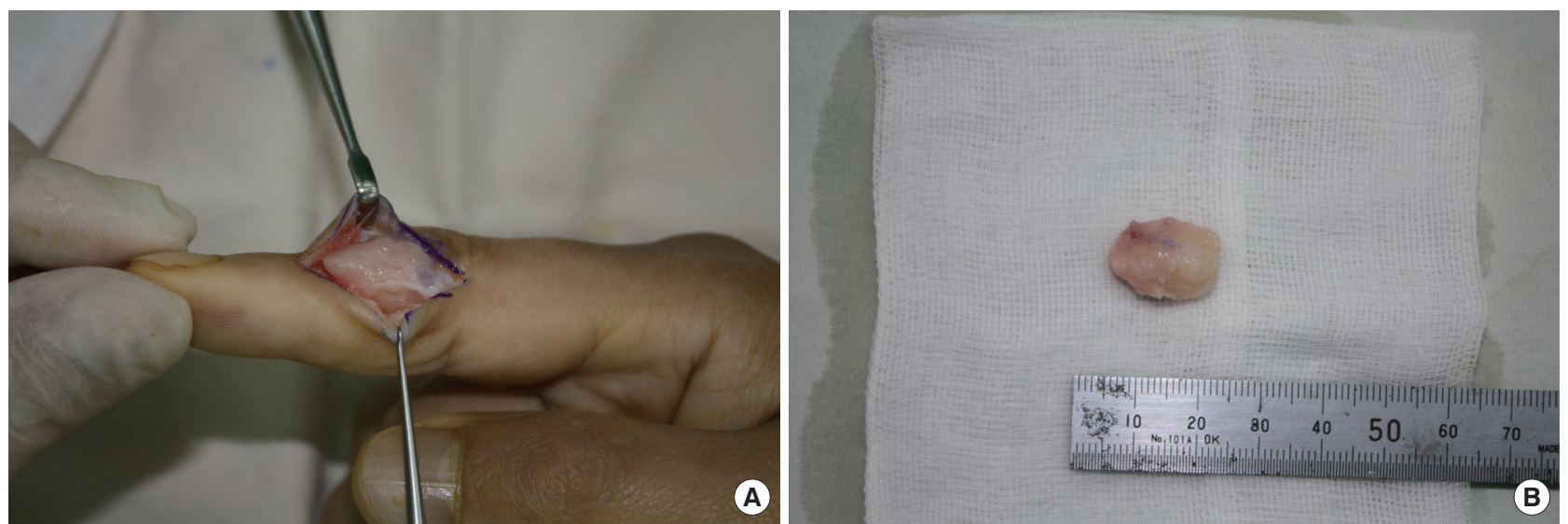

Fig. 2.

Intraoperative findings. (A) Incision planning with exposure of the mass. (B)

(B) Resected specimen $(2 \mathrm{~cm} \times 1 \mathrm{~cm} \times 1 \mathrm{~cm})$.

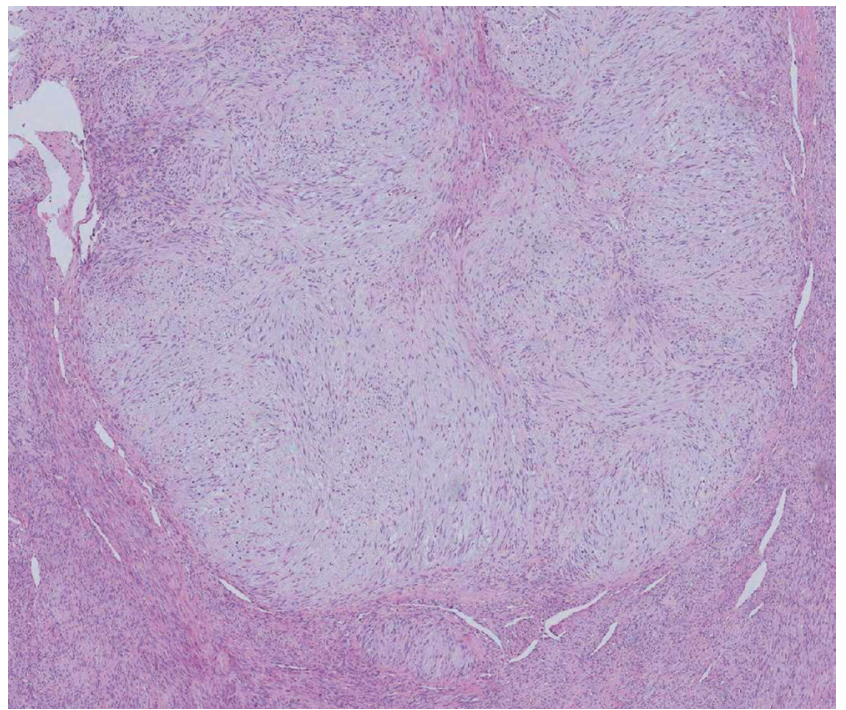

Fig. 3.

Histopathology and immunohistochemistry findings. The tumor shows alternating hypocellular and hypercellular areas. The hypocellular areas form lobules composed of loosely arranged cells in the grayblue chondromyxoid matrix and surrounded by hypercellular spindle cells $\left(H \& E_{1} \times 40\right)$.
There is no gender-related difference. To date, no definite etiologies have been documented. It is known that approximately $75 \%$ of the total cases of CMF affect the bones of the lower extremities. In particular, it occurs most frequently in the tibia and femur around the knee joint. Thus far, its incidence in the hand has been described to be very rare. Most cases of CMF typically originate from the metaphysis and may then extend to the epiphysis and diaphysis. The most common clinical manifestations of CMF include swelling and pain at the sites of primary tumor growth, but there are also some asymptomatic cases. Plain radiography shows that CMF has a round-to-oval medullary lesion with a well-defined margin and is parallel to the long axis of the bone. The tumor with a thin scalloped, sclerotic border has an eccentric location in the metaphysis and a translucent, osteolytic, bubbly appearance. Furthermore, it shows a slightly expansile growth to the adjacent soft tissue. For establishing the diagnosis of chondromyxoid fibroma, histopathological examinations are essential. In a nutshell, CMF is a firm, white, lobulated, wellcircumscribed solid tumor mass that is sharply demarcated from the adjacent bone marrow. Light microscopy revealed that CMF is composed of three zones: myxomatous, fibrous, and chondroid zones. Histopathologically, it is characterized by the multilobular arrangement of stellate or spindle-shaped cells in an abundant myxoid background or chondroid intracellular material. These lobules are composed of the central hypocellular area and the peripheral hypercellular area. Surgical excision is the first-line choice for chondromyxoid fibroma, for which only simple curettage is performed or a bone graft is used 
for filling the cavitary defect following curettage. Although variable depending on the reports, the recurrence is estimated at approximately $25 \%$.

Postoperatively, regular follow-up including radiography is necessary. A good prognosis of CMF has been documented. In addition, it has been reported that CMF shows no distant metastasis [1-5].

\section{References}

1. Hau MA, Fox EJ, Rosenberg AE, et al. Chondromyxoid fibroma of the metacarpal. Skeletal Radiol 2001;30:71921.
2. Nalbantoglu U, Aktas S, Peker KR. Chondromyxoid fibroma involving the entire metacarpal: a case report. J Hand Surg Am 2005;30:1083-6.

3. Kirin I, Jurisic D, Mokrovic H, et al. Chondromyxoid fibroma of the second metacarpal bone: a case report. Coll Antropol 2011;35:929-31.

4. Durr HR, Lienemann A, Nerlich A, et al. Chondromyxoid fibroma of bone. Arch Orthop Trauma Surg 2000; 120:42-7.

5. De Mattos CB, Angsanuntsukh C, Arkader A, et al. Chondroblastoma and chondromyxoid fibroma. J Am Acad Orthop Surg 2013;21:225-33. 